\title{
A história da imigração de brasileiros para o Sul da Flórida
} The history of Brazilian immigration to South Florida

\author{
Alex Guedes Brum*
}

\begin{abstract}
Resumo
Atualmente, entre três a quatro milhões de brasileiros residem no exterior. A comunidade brasileira na Flórida - com aproximadamente 350 mil compatriotas vivendo no estado - é uma das maiores no estrangeiro. 0 presente artigo tem como objetivo analisar a história da imigração de brasileiros para o Sul da Flórida durante o período de tempo compreendido entre 1980 até 2016. Para tanto, foram realizadas, além de pesquisa bibliográfica, entrevistas semiestruturadas com lideranças da referida comunidade. Empregou-se o método bola de neve. Concluiu-se que a história da imigração de brasileiros pode ser divida em três ondas e que, no presente momento, ocorre a terceira onda. O que diferencia o período atual dos anteriores é a chegada, em grande número, de brasilieiros com grau superior de instrução e/ou com alta qualificação nas diversas áreas de sua atuação profissional.
\end{abstract}

Palavras-chave: migrações internacionais; emigração de brasileiros; imigração; Flórida.

\begin{abstract}
Currently, between three and four million Brazilians live abroad. The Brazilian community in Florida - with approximately 350,000 compatriots living in the state - is one of the largest overseas. This article aims to analyze the history of immigration of Brazilians to South Florida during the time period between 1980 and 2016. For this purpose, in addition to bibliographical research, semistructured interviews were conducted with community leaders. The snowball method was employed. It was concluded that the history of the immigration of Brazilians can be divided into three waves and that, at the moment, the third wave occurs. What differentiates the current period from the previous ones is the arrival, in great number, of Brazilians with superior degree of education and/or with high qualification in the diverse areas of their professional performance.
\end{abstract}

Keywords: international migration; emigration of Brazilians; immigration; Florida.

${ }^{*}$ Doutorando em História, Política e Bens Culturais pela Fundação Getúlio Vargas (FGV). E-mail: alexbrum23@outlook.com 


\section{Introdução}

Atualmente, entre três a quatro milhões de brasileiros residem no exterior. ${ }^{1}$ Embora a emigração atinja apenas entre $1 \%$ a $2 \%$ dos cerca de 200 milhões de indivíduos que compõem a população do país, isso significa um deslocamento de um grande número de pessoas. ${ }^{2}$ A comunidade brasileira nos Estados Unidos, com aproximadamente um milhão e quatrocentos mil brasileiros ${ }^{3}$, é a numericamente mais expressiva em relação às outras brasileiras ao redor do mundo. Estima-se que destes, trezentos e cinquenta mil vivam na Flórida.

Tais dados permitem dizer que há mais nacionais no exterior do que vivendo em Brasília, terceira cidade brasileira em população. E que, somente na Flórida, há tantos nacionais quanto habitantes de uma capital estadual como Vitória, no Espírito Santo. ${ }^{4}$

Este artigo tem como objetivo analisar a história da imigração de brasileiros para o Sul da Flórida durante o período de tempo compreendido entre 1980 a 2016. Para tanto, foram realizadas, além de pesquisa bibliográfica, entrevistas semiestruturadas com lideranças da referida comunidade.

Estas linhas iniciais buscam apresentar, na primeira parte deste artigo, a metodologia utilizada neste trabalho e, em seguida, o Brasil como um país emigração. A terceira parte aborda brevemente a presença brasileira no Sul da Flórida. Logo após, é analisada a história da imigração de brasileiros para a supramencionada região estadunidense.

\section{Metodologia}

A fim de analisar a história da imigração de brasileiros para o Sul da Flórida, foram realizadas, além de pesquisa bibliográfica, entrevistas semiestruturadas com lideranças da referida comunidade. As entrevistas com informantes-chave permitiram o registro de uma história "em construção" da presença brasileira na Flórida. Esta, por ser recente, conta com poucos registros escritos.

\footnotetext{
${ }^{1}$ MRE. Diplomacia Consular. Brasília: FUNAG, 2012.

${ }^{2}$ MARGOLIS, Maxine L. Goodbye, Brazil: emigrantes brasileiros no mundo. São Paulo: Contexto, 2013, p. 28. ${ }^{3}$ Disponível em: http://www.brasileirosnomundo.itamaraty.gov.br/a-comunidade/estimativas-populacionais-das-comunidades/Estimativas\%20RCN\%202015\%20-\%20Atualizado.pdf.

${ }^{4}$ BRUM, Alex Guedes. Brasileiros no exterior: o caso da Flórida. Rio de Janeiro: Editora Multifoco, 2018, p. 241.
} 
Para a realização das entrevistas, empregou-se a técnica da amostragem em bola de neve (em inglês, snowball), originalmente introduzida por Coleman ${ }^{5}$ e Goodman ${ }^{6}$ como um meio para estudar a estrutura das redes sociais. Com o objetivo de executar a amostragem em bola de neve, são selecionados informantes-chave, nomeados como "sementes", que, por sua vez, são incumbidos de indicar a partir de seus contatos outros indivíduos para a amostra. Segue-se assim, sucessivamente, até que se alcance o tamanho amostral desejado. ${ }^{78} \mathrm{Em}$ função da sua estratégia de recrutamento, o método bola de neve é considerado não probabilístico, visto que não é possível determinar a probabilidade de seleção de cada participante na amostra. ${ }^{9}$

Como aponta Bernard ${ }^{10}$, esta técnica é um método de amostragem de rede útil para estudar populações difíceis de serem acessadas ou estudadas (Hard-to-find or hard-to-study populations) ou que não há precisão sobre sua quantidade. Para Vinuto ${ }^{11}$, a amostragem em bola de neve também é útil para estudar questões delicadas, de âmbito privado e, portanto, que requer o conhecimento das pessoas pertencentes ao grupo ou reconhecidos por estas para localizar informantes para estudo.

Do ponto de vista dos procedimentos técnicos, as entrevistas foram gravadas e transcritas, sendo posteriormente textualizadas; isto é, sofreram um processo de edição, através da qual a voz do entrevistador foi suprimida e o texto foi trabalhado para a apresentação no corpo do trabalho.

As entrevistas foram realizadas com lideranças comunitárias durante a pesquisa de campo na Flórida, em setembro de 2016. No referido estado norte-americano, foi possível ter contato com os membros da comunidade brasileira, o que facilitou na construção de uma relação de confiança com os líderes comunitários, fundamental para o sucesso das entrevistas.

${ }^{5}$ COLEMAN, James Samuel. "Relational Analysis: The Study of Social Organizations with Survey Methods". In: Human Organization. 1958-59, v. 17, p. 28-36.

${ }^{6}$ GOODMAN, Leo A. “Snowball Sampling”. In: Annals of Mathematical Statistics. 1961, v. 32, p. 148-170.

${ }^{7}$ DEWES, João Osvaldo. Amostragem em bola de neve e respondent-driven sampling: uma descrição dos métodos. Porto Alegre: Monografia em bacharelado em Estatística. UFRGS, 2013.

${ }^{8}$ VINUTO, Juliana. “A amostragem em bola de neve na pesquisa qualitativa: um debate em aberto". In: Temáticas. Campinas, 2014, v. 22, n. 44, p. 203.

${ }^{9}$ ALBUQUERQUE, Elizabeth Maciel de. Avaliação de Amostragem "Respondent-Driven Sampling" na Estimação de Prevalências de Doenças Transmissíveis em Populações Organizadas em Redes Complexas. Rio de Janeiro: Dissertação de mestrado em Ciências na área de Saúde Pública. Fundação Oswaldo Cruz, 2009.

${ }^{10}$ BERNARD, Harvey Russel. Research methods in anthropology: qualitative and quantitative approaches. Lanham: AltaMira Press, 2005.

${ }^{11}$ VINUTO, op. cit., p. 201-218. 


\section{O Brasil como um país de emigração}

Até a década de 1980, as questões migratórias interessavam ao Brasil na perspectiva de país de destino. Ao longo da sua história, o Brasil foi um país receptor de imigrantes, tendo as migrações contribuído para formar nossa nacionalidade. ${ }^{12}$

A significativa diversidade e riqueza cultural brasileira são o legado de várias ondas migratórias, de continentes e países diversos, que, ao longo dos séculos, por diferentes meios e razões, ocuparam e colonizaram o território brasileiro. Partiram de migrantes os primeiros relatos da terra brasileira e do encontro entre a cultura nativa e a do colonizador, como a Carta de Pero Vaz de Caminha e os relatos de Manuel da Nóbrega e outros. A cultura brasileira reflete, por igual, os costumes e tradições indígenas, assim como a história trazida para o Brasil pelos mais de quatro milhões de africanos escravizados, durante a vigência da escravatura no país. Entre 1836 e 1980, houve grande diversidade de raças, povos e nacionalidades que imigraram para o Brasil. Os maiores contingentes, nesse período, foram de portugueses, italianos, espanhóis, alemães, japoneses, russos, austríacos, sírio-libaneses, poloneses e franceses. ${ }^{13}$

De acordo com Teresa Sales ${ }^{14}$, é a partir de meados dos anos 1980 que a emigração brasileira assume proporções significativas. Essa afirmação foi confirmada pelo World Economic and Social Survey 2004, relatório elaborado pela ONU. De acordo com tal estudo, desde o primeiro quinquênio dos anos 1980, o Brasil começa a ter saldos migratórios constantemente negativos, característica que lhe dá, atualmente, a classificação de "país de emigração". ${ }^{15}$

Embora ainda recebesse imigrantes de diversas origens, o número de brasileiros emigrantes passou a superar o de estrangeiros chegados ao país, e, acompanhando tendência verificada em outros países em desenvolvimento (PED), sobretudo na América Latina e Caribe, o Brasil tornou-se exportador líquido de mão de obra. ${ }^{16} \mathrm{O}$ País se deu conta, paulatinamente, de que se tornara também um país de emigração. ${ }^{17}$ Como aponta Bernadete Beserra,

\footnotetext{
${ }^{12}$ FARIA, Maria Rita Fontes. Migrações internacionais no plano multilateral: reflexões para a política externa brasileira. Brasília: FUNAG, 2015.

${ }^{13}$ Ibidem, p. 65-66.

${ }^{14}$ SALES, Tereza. "Brasileiros nos Estados Unidos". In: I Conferência sobre as Comunidades Brasileiras no Exterior, Brasileiros no Mundo. Brasília: FUNAG, 2009.

${ }^{15}$ ONU - DEPARTAMENT OF ECONOMIC AND SOCIAL AFFAIRS. World Economic and Social Survey - 2004, p. 36. Disponível em: http://www.un.org/desa/analysis/wess/. Acesso em: 10 out. 2016.

${ }^{16}$ FARIA, op. cit.

${ }^{17}$ MAIA, Oto Agripino. "Brasileiros no Mundo: O Ambiente Mundial das Migrações e a Ação Governamental”. In: I Conferência sobre as Comunidades Brasileiras no Exterior, Brasileiros no Mundo. Brasília: FUNAG, 2009, p. 29-30.
} 
No final da década de 1980, a imprensa nacional começa a publicar suas primeiras reportagens sobre a emigração brasileira. Até então, tal fenômeno era praticamente impensável. Raras exceções incluíam brasileiros vivendo em outros países contra suas vontades, como no caso dos expatriados da ditadura militar ou dos que precisavam viver no exterior porque suas carreiras requeriam tal empreendimento. Apesar da sua história de país receptor de imigrantes, e contra todas as expectativas criadas pelas ideologias nacionalistas brasileiras, a emigração tem crescido consistentemente desde o período mencionado acima. ${ }^{18}$

\section{A motivação da emigração dos brasileiros é predominantemente econômica. ${ }^{19,20}$}

Há fundamento em considerar a hiperinflação e as condições de incerteza econômica que a acompanham como as maiores causas para o crescente êxodo brasileiro, já que as comportas da emigração se abriram em 1986, mais ou menos na mesma época em que falhou o Plano Cruzado, o primeiro esforço do governo para lidar com a inflação galopante. ${ }^{21}$

No entanto, além das sucessivas crises econômicas que acometeram o país nos anos 80 (considerados a "década perdida") e 90, a transformação do Brasil em exportador líquido de mão de obra está associada a fatores como:

1) a maior disponibilidade de informações sobre oportunidades de trabalho no exterior, resultante da modernização das tecnologias de informação e comunicação - essa causa não é exclusiva, naturalmente, do fenômeno identificado no Brasil; 2) fatores históricos e culturais relacionados à presença, no Brasil, de significativo número de descendentes de imigrantes, sobretudo de europeus, o que pode haver facilitado o contato com as sociedades e o mercado de trabalho nos países de origem das ondas imigratórias anteriores que se haviam destinado ao país, em particular oriundas de Portugal, Espanha, Itália, Alemanha e Japão; 3) a crescente insegurança urbana em várias cidades brasileiras; e 4) no caso da imigração para países vizinhos (particularmente Paraguai, Bolívia, Suriname e as Guianas), a percepção de vantagens econômico-comerciais, como a existência de terra férteis e baratas, oportunidades relacionadas ao garimpo de ouro ou devido a fatores fundiários, como a concentração de terras na região Sul do Brasil. ${ }^{22}$

Em suma, diferentemente das análises conjunturais que associavam exclusivamente a saída de brasileiros à "década perdida" ou à conjuntura

\footnotetext{
${ }^{18}$ BESERRA, Bernadete. Brasileiros nos Estados Unidos: Hollywood e Outros Sonhos. Fortaleza/São Paulo/ Santa Cruz: Editora UFC/UNISC/HUCITEC, 2005, p. 20-21.

${ }^{19}$ MARTES, Ana Cristina Braga. Brasileiros nos Estados Unidos: um estudo sobre imigrantes em Massachusetts. São Paulo: Paz e Terra, 1999.

${ }^{20}$ SALES, Teresa. Brasileiros longe de casa. São Paulo: Cortez Editora, 1999.

${ }^{21}$ MARGOLIS, op. cit., p. 34.

${ }^{22}$ FARIA, op. cit., p. 67.
} 
político-econômica do Governo Collor (1990-1992), questões estruturais de ordem social, associadas, ao fenômeno da globalização, foram se configurando, progressivamente, como a principal causa da saída de brasileiros, o que indicava que a emigração tinha "vindo para ficar". ${ }^{23}$

Atualmente, entre três a quatro milhões de brasileiros residem no exterior. ${ }^{24}$ A comunidade brasileira nos Estados Unidos da América, com aproximadamente um milhão e quatrocentos mil brasileiros, é a numericamente mais expressiva em relação às outras brasileiras ao redor do mundo. ${ }^{25}$ Estima-se que destes, trezentos e cinquenta mil vivam na Flórida. ${ }^{26}$

\section{Um Brasil no Sul da Flórida}

O estado da Flórida se divide em 67 condados e os brasileiros podem ser encontrados por todo o território, principalmente nos condados de MiamiDade, Broward e Palm Beach e em cidades como Orlando e Fort Meyer. Este trabalho se limita apenas aos três primeiros, que se localizam no extremo Sudeste do estado (Mapa 1). O recorte escolhido se explica por várias razões. Uma delas é que Miami-Dade, Broward e Palm Beach concentram a maior quantidade de brasileiros na Flórida. Além disso, Miami tem uma história de recepção da comunidade brasileira mais antiga do que outros locais, a qual foi iniciada com a entrada de empresas multinacionais que importaram business men brasileiros. Eles trouxeram suas famílias e contribuíram para o início de uma rede de imigração de seus conterrâneos. ${ }^{27}$

\footnotetext{
${ }^{23}$ PATARRA, Neide Lopes. "Governabilidade das Migrações Internacionais e Direitos Humanos: o Brasil como País de Emigração”. In: I Conferência sobre as Comunidades Brasileiras no Exterior, Brasileiros no Mundo. Brasília: FUNAG, 2009, p. 190.

${ }^{24}$ MRE, op. cit.

${ }^{25}$ Segundo estimativas populacionais elaboradas pelo Itamaraty, após os Estados Unidos da América, os países que abrigam as maiores concentrações de brasileiros no exterior são: Paraguai $(332,042)$; Japão (170,229); Reino Unido (120.000) e Portugal $(116,271)$. Disponível em: http://www.brasileirosnomundo. itamaraty.gov.br/a-comunidade/estimativas-populacionais-das-comunidades/Estimativas\%20RCN\%20 2015\%20-\%20Atualizado.pdf. Acesso em: 15 abr. 2018.

${ }^{26}$ MARGOLIS, op. cit.

${ }^{27}$ MAGALHÃES, Valéria Barbosa de. O Brasil no Sul da Flórida: subjetividade, identidade e memória. São Paulo: Letra e Voz, 2011.
} 
Mapa 1: Condados da Flórida

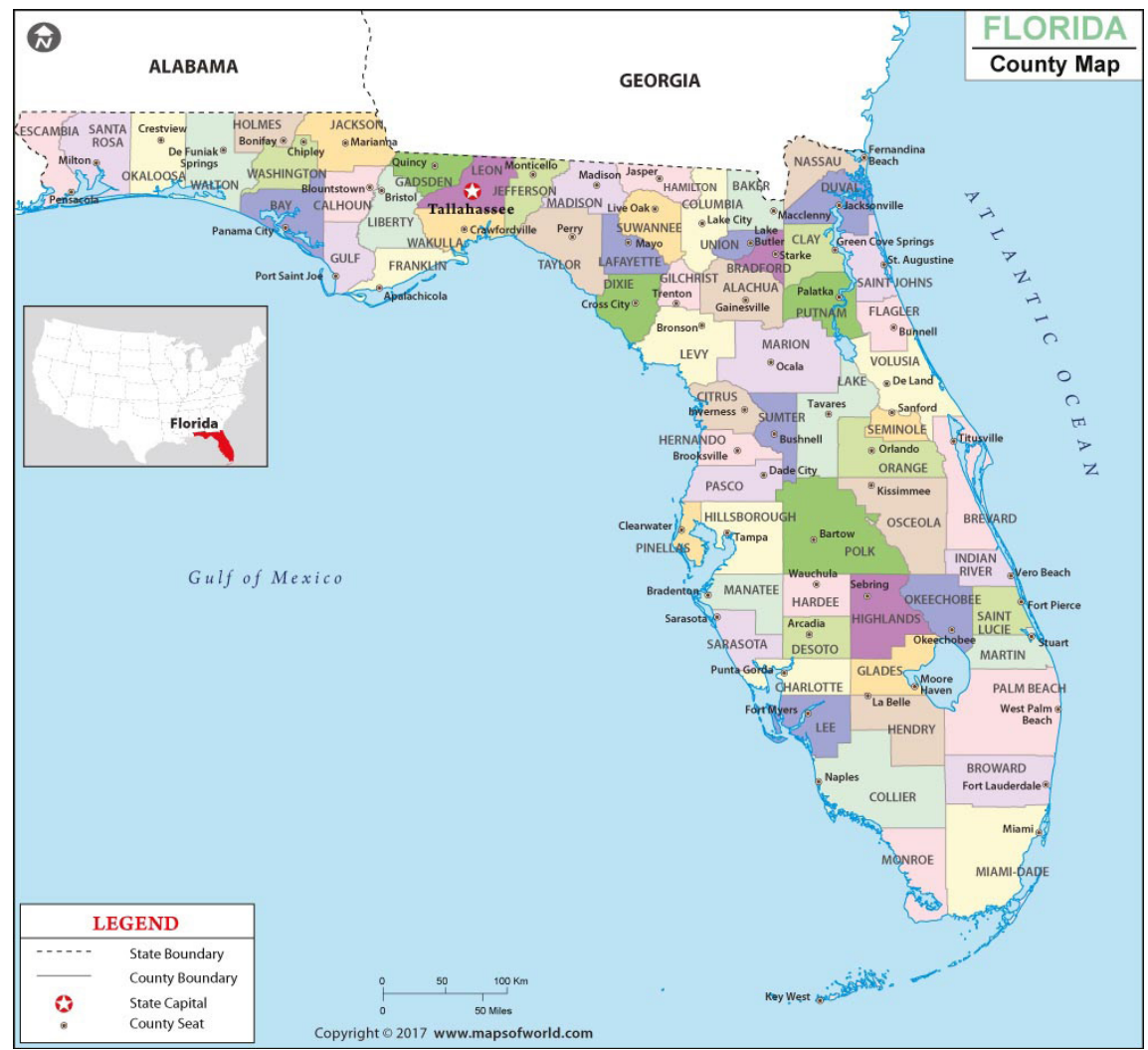

Fonte: Disponível em: https://www.mapsofworld.com/usa/states/florida/florida-county-map.html. Acesso em: 25 abr. 2018.

Em 2014, foi elaborado pelo Conselho de Cidadãos da Flórida, órgão apolítico de aconselhamento ao Consulado-Geral do Brasil em Miami, um mapeamento inédito sobre a comunidade brasileira na Flórida. 0 estudo demonstrou que os brasileiros que fazem parte da referida comunidade possuíam renda e grau de escolaridade bastante acima da média nacional, muitos falam dois ou três idiomas, e mostram interesse em manter suas raízes com o Brasil. ${ }^{28}$

Como demonstra o gráfico 1, a maioria (82\%) dos entrevistados durante o mapeamento elaborado pelo Conselho de Cidadãos em 2014 vinha de Broward, Miami-Dade e Palm Beach.

\footnotetext{
${ }^{28}$ Disponível em:http://miami.itamaraty.gov.br/pt-br/mapeamento_comunidade_brasileira_na_florida. xml. Acesso em: 25 abr. 2018.
} 
Gráfico 1: Condado de residência dos brasileiros na Flórida

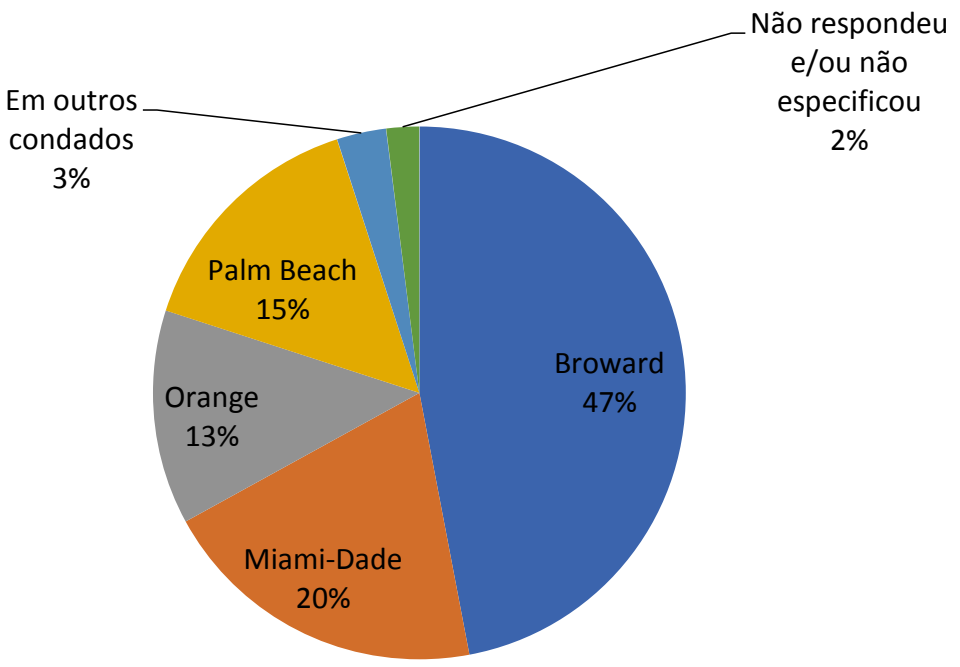

Fonte: Conselho de Cidadãos da Flórida. Projeto Mapeamento. 2014. Disponível em: https:// sistemas.mre.gov.br/kitweb/datafiles/Miami/pt-br/file/Resultado_graficos_pizza(1).pdf. Acesso em: 15 abr. 2018.

Quanto às cidades, os brasileiros na Flórida se encontram em maior número em Tampa, Boca Raton, Pompano Beach, Fort Lauderdale, Orlando e Miami. ${ }^{29}$ Das dez cidades com maior porcentagem de população residente brasileira nos Estados Unidos, cinco estão localizadas na Flórida. Loch Lomond, uma região censo-designada no condado de Broward, localizada a apenas 4 $\mathrm{km}$ da cidade de Pompano Beach, é lar da maior porcentagem de brasileiros vivendo nos Estados Unidos, contabilizando 14,9\% da população local. As demais são respectivamente: Mexico Beach, com 8\%, na sexta posição; BonnieLoch-Woodsetter North, com 7.3\%, em oitavo; e Deerfield Beach, em nono, com $7 \%{ }^{30}$

No condado de Broward, a cidade de Pompano Beach é a que mais possui residentes brasileiros. Como ressalta Oliveira, "muito mais do que uma questão numérica, esta cidade surpreende por ser como que um verdadeiro pedaço do Brasil incrustado na Flórida". ${ }^{31}$

\footnotetext{
${ }^{29}$ OLIVEIRA, Adriana Capuano de. Bienvenido a Miami: a inserção dos imigrantes brasileiros nos Estados Unidos. Campinas: Tese de doutorado em Sociologia. UNICAMP, 2004.

${ }^{30}$ Disponível em: http://www.city-data.com/top2/h153.html. Acesso em: 16 abr. 2018.

${ }^{31}$ OLIVEIRA, op. cit., p. 259.
} 
A marcante presença de brasileiros em Broward permite que uma pessoa que more em Pompano ou Deerfield Beach possa viver nos Estados Unidos durante anos, consumindo somente produtos brasileiros, sem nunca precisar falar inglês ou espanhol ou ter contato com pessoas de outra nacionalidade, como é o caso de muitos de meus entrevistados. Em Miami-Dade, quem vem do Brasil terá que defrontar, pelo menos uma vez por dia, com alguém de outra cultura, seja na rua, no trabalho ou no comércio. ${ }^{32}$

O Sul da Flórida possui uma grande variedade de negócios de propriedade de brasileiros, incluindo postos de gasolina, restaurantes, lanchonetes, agências de viagem e de remessa de dinheiro, companhias de mudança, lojas de telefones celulares e de móveis, e, é claro, as lojas que vendem artigos do Brasil. A área também é o lar de muitos profissionais brasileiros médicos, dentistas, advogados e contadores, que têm, em grande parte, uma clientela brasileira. ${ }^{33}$

\section{A imigração de brasileiros para o Sul da Flórida}

Antes da década 1980, haviam relativamente poucos brasileiros no Sul da Flórida. Como afirma Valéria Magalhães, a "imigração do Brasil para a Flórida iniciou-se na década de 1980 e consolidou-se nos anos 1990 e, por isso, podemos descrevê-la como um movimento recente" ${ }^{34}$ Registros oficiais são escassos ou inexistentes, como mostra a falta de estatísticas confiáveis.

De acordo com Bloem ${ }^{35}$, a imigração brasileira para a Flórida ocorreu em três ondas ${ }^{36,37}$ : as décadas de 1980 e 1990 (especialmente a década de 1990) trouxeram principalmente a classe média brasileira; a década seguinte (final da década de 1990 e início da década de 2000 até a crise econômica de 2007-2008)

\footnotetext{
${ }^{32}$ MAGALHÃES, Valéria Barbosa de. "Imigração brasileira para o Sul da Flórida”. In: Proj. História. São Paulo, 2003, v. 27, p. 287-288.

${ }^{33}$ MARGOLIS, op. cit., 2013.

${ }^{34}$ MAGALHÃES, O Brasil no Sul da Flórida... op. cit., p. 55.

${ }^{35}$ BLOEM, Taylor M. Impacts of Brazilian Businesses and Brazilian Immigrant Organizations in South Florida. Tucson: dissertação de mestrado em Artes. Universidade do Arizona, 2015.

${ }^{36}$ Bloem adota o conceito de classes sociais que classifica a sociedade em letras de A a E. Essa classificação é a que mais se assemelha às definições utilizadas por seus entrevistados. $\mathrm{O}$ autor considera a classe $\mathrm{A}$ (renda mensal acima de 10.200 reais) como a classe alta, classe B (renda mensal acima de 5.100 reais) como classe média, classes C (renda mensal acima de 2.040 reais) e D (renda mensal acima de 1.020) como classes trabalhadoras, e classe E (renda mensal abaixo de 1.020) como classe baixa.

${ }^{37}$ Para Bloem, essas ondas não abrangem os antecedentes socioeconômicos de todos os imigrantes brasileiros na Flórida durante esses períodos de tempo. Em vez disso, são generalizações sobre os níveis socioeconômicos de muitos imigrantes brasileiros durante esse tempo, e destinam-se a ajudar a esboçar um perfil aproximado da imigração brasileira para a área nos últimos 30 anos. Segundo o autor, seus perfis são baseados em observações feitas por muitos de seus informantes chaves entrevistados para seu trabalho que residem na área desde os anos 1980 e têm como objetivo prover uma visão geral da população imigrante brasileira no Sul da Flórida.
} 
trouxe multidões de brasileiros, a maioria da classe trabalhadora brasileira buscando oportunidades de negócios em trabalho manual; e a terceira onda de imigração, que vem ocorrendo nos últimos anos, está trazendo muitos brasileiros das classes mais altas. Tais ondas podem ser melhor compreendidas através da análise do quadro a seguir (Quadro I):

Quadro 1 - Ondas da imigração brasileira para o Sul da Flórida

\begin{tabular}{|c|c|c|c|}
\hline Onda & Período & Eventos marcantes & $\begin{array}{c}\text { Características } \\
\text { socioeconômicas } \\
\text { predominantes dos } \\
\text { imigrantes }\end{array}$ \\
\hline Primeira onda & $\begin{array}{c}\text { Décadas de } \\
1980 \text { e } 1990 \\
\text { (principalmente } \\
\text { década de 1990). }\end{array}$ & $\begin{array}{l}\text { Entrada de empresas } \\
\text { multinacionais (a } \\
\text { partir da década de } \\
\text { 1980); Plano Collor (em } \\
12 \text { de abril de 1990); e } \\
\text { a paridade do real em } \\
\text { relação ao dólar (em 1º } \\
\text { de julho de 1994). }\end{array}$ & Classe média \\
\hline Segunda onda & $\begin{array}{c}\text { Final da década } \\
\text { de } 1990 \text { até } \\
\text { 2007-2008. }\end{array}$ & $\begin{array}{l}\text { Crise econômica do } \\
\text { Brasil provocada } \\
\text { pelo Plano Real (e } \\
\text { acentuada após 1999) } \\
\text { e atentados de } 11 \text { de } \\
\text { Setembro de } 2001 .\end{array}$ & Classe trabalhadora \\
\hline Terceira onda & A partir de 2008 & $\begin{array}{l}\text { Crise econômica } \\
\text { no Brasil (desde } \\
\text { 2014); processo de } \\
\text { impeachment de Dilma } \\
\text { Roussef (iniciado em } \\
\text { dezembro de } 2015 \text { e } \\
\text { encerrado em agosto } \\
\text { de 2016); e eleição de } \\
\text { Donald Trump, em } \\
\text { novembro de } 2016 .\end{array}$ & Classes altas \\
\hline
\end{tabular}

Fonte: BLOEM, Taylor M. Impacts of Brazilian Businesses and Brazilian Immigrant Organizations in South Florida. Tucson: dissertação de mestrado em Artes. Universidade do Arizona, 2015. 


\section{Primeira onda}

Miami tem uma história de recepção da comunidade brasileira mais antiga do que outros locais, a qual foi iniciada com a entrada de empresas multinacionais que "importaram" business men brasileiros. Eles trouxeram suas famílias e contribuíram para o início de uma rede de imigração de seus conterrâneos. ${ }^{38}$

A partir da década de 1980, empresas brasileiras como VASP, TAM, Odebrecht e Banco do Brasil transferiram funcionários para Miami. ${ }^{39}$ Sobre esse período, Heliana recorda que:

as empresas começaram a transferir funcionários, então ficou uma grande concentração em Miami, os bancos, o Banco do Brasil, o Bonespa na época, tinha um grupo grande em Miami. Outras empresas, como a Embraer, tinham funcionários transferidos, os próprios funcionários do consulado, então era uma população flutuante, que não sabia se ia ficar ou não, eram contratos temporários. ${ }^{40}$

Em torno deles, outra rede de imigrantes se formou, pois outros compatriotas imigraram como mão de obra de apoio (babás, motoristas, importadores de bens brasileiros, etc.).

Segundo Magalhães, o Plano Collor, instituído em 1990, foi importante para a entrada de brasileiros no Sul da Flórida porque "abriu as importações, propiciando um impulso de negócios entre Brasil e Estados Unidos. Ao mesmo tempo, o confisco das poupanças foi razão para que muitos decidissem ir embora do Brasil". ${ }^{41}$ Nas palavras da autora, "para a maioria, [...] o Plano Collor foi a gota d'água para deixar o Brasil". ${ }^{42}$ "Oscilações econômicas impulsionaram desiludidos a tentarem a vida no exterior e incentivaram outros a realizarem negócios na Flórida". ${ }^{43}$ Como aponta Bloem,

most of my interview participants agreed that prior to the late-1990s, Brazilian immigrants to South Florida tended to hail from the Brazilian middle class. These migrants were, for the most part, educated, semi-affluent Brazilians who came to South Florida disillusioned with Brazil's political and economical situation of the time. They migrated to the United States in order to maintain middle-class lifestyles, which was a difficult undertaking in the Brazil of the 1980s and 1990s (a country revaged

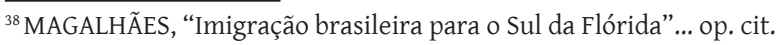

${ }^{39}$ MAGALHÃES, O Brasil no Sul da Flórida... op. cit.

${ }^{40}$ Apud MAGALHÃES, O Brasil no Sul da Flórida... op. cit, p. 56.

${ }^{41}$ Ibidem, p. 57.

${ }^{42}$ Ibidem, p. 58.

${ }^{43}$ Ibidem, p. 58.
} 
by hyperinflation and unemployment). In fact, several of the Brazilian immigrant organization leaders and business executive that I interviewed for this work came to South Florida during that timeframe and fit this description. ${ }^{44}$

O boom do turismo brasileiro em downtown Miami, que teve seu ápice na época da paridade do real com o dólar (a partir de 1º de julho de 1994), assim como as mudanças de hábitos de consumo no Brasil, tiveram como consequência

a abertura de uma infinidade de lojas para turistas e sacoleiros. Isso iniciou um nicho de mercado de trabalho para "indocumentados" de língua portuguesa e propiciou uma nova rede de entrada de imigrantes. Na época, as sacoleiras brasileiras [...] eram presença constante em downtown. Elas compravam no atacado produtos que eram novidade e os revendiam no Brasil. Entre os principais produtos procurados pelos brasileiros, estavam os eletrônicos, perfumaria, e acessórios de vestuário. ${ }^{45}$

Em entrevista para Magalhães, o empresário Edson aponta que, em 1990, downtown Miami recebia turistas que iam para Disney e que passavam por lá para fazer compras. Ele conta que essa área tinha dez vezes mais lojas do que tem hoje:

Eu lembro que cheguei aqui em junho de 1990, alguns meses depois saiu uma estatística de quantos brasileiros vieram naquele ano. $\mathrm{O}$ downtown Miami tinha recebido 100 mil turistas brasileiros em julho porque na época o mercado era muito fechado e o pessoal vinha comprar vídeo, ia à Disney. Brasileiro gosta de viajar quando tem a oportunidade financeira. Hoje em dia, não dá nem para fazer comparação com o que era downtown. O que você de lojas brasileiras, tinha dez vezes mais, só voltadas para o turismo. A Vitors, que era marco, uma loja de departamentos, tinha de tudo o que o brasileiro queria. Tinha a Peninha, uma porção de lojas. Não lembro muito os nomes, tinha no mínimo umas vinte ou trinta, entre pequenas e grandes. Das grandes, a mais conhecida era a Vitors e tinha uma outra, a Alô Brasil. Em 1994, começou a mudar por causa do dólar. Teve época que a nossa moeda começou a ser oferecida no Brasil. ${ }^{46}$

A desvalorização do real em relação ao dólar (em 15 de janeiro de 1999) marcou o fim da "era downtown", quando lojas brasileiras foram fechadas e, consequentemente, muitos brasileiros (em geral, "indocumentados") perderam seus empregos. Alguns desses desempregados voltaram ao Brasil, mas parte deles foi realocada em outros setores do mercado de trabalho como mão de obra não qualificada. A permanência de alguns deles em Miami parece ter

\footnotetext{
${ }^{44}$ BLOEM, op. cit., p. 24.

${ }^{45}$ MAGALHÃES, O Brasil no Sul da Flórida... op. cit., p. 58-59.

${ }^{46}$ Apud ibidem, p. 60.
} 
sido determinada, prioritariamente, pela espera de resultado de pedidos de legalização. Já os donos das lojas voltaram para o Brasil ou tentaram novos negócios com importação e exportação em Miami. Atualmente, o comércio brasileiro em downtown é insignificante se comparado àquele existente no final dos anos 1980 e começo da década de 1990. A desvalorização da moeda em 1999 reduziu o turismo especializado do Brasil para Miami e mudou o perfil da imigração. ${ }^{47}$

\section{Segunda onda}

De acordo com diversos entrevistados por Bloem ${ }^{48}$, a segunda onda de imigração brasileira para a Flórida ocorreu nos primeiros sete a oito anos do novo milênio (entre 2000-2008), quando a economia norte-americana estava indo melhor do que a brasileira. Redes sociais de migrantes produzidas por fluxos migratórios anteriores do Brasil provavelmente abriram as portas da Flórida para a classe trabalhadora. Como consequência, incontáveis brasileiros se estabeleceram no norte do condado de Broward (especialmente Pompano Beach) e no sul do condado de Palm Beach (principalmente Boca Raton).

De acordo com Ronaldo Parente, professor de economia na Florida International University,

That was a time when there were no jobs [in Brazil] and all the working class started
moving out of Brazil... I would say between 2000-2007... There were a lot of people moving
to the US to work in construction and other high labor intensive jobs. See, there was a
boom in construction [in US] from 2000-2008 and there was no labor in Brazil, so one guy
would come and more would follow... In Florida they [the Brazilians] basically dominated
the tile market, and in the north they dominated the framing market... their goal was
to come here and work 14 hours a day, 7 days a week, so they could go back to Brazil
with enough money to open their own business and be settled. A lot of people came, just
worked and worked... then in 2008 with the crash, most of them moved back [to Brazil]
and started opening up businesses. Now the Brazilian economy to go down again and
you can see some flux of people trying to move back to US. ${ }^{49}$

A segunda onda da imigração brasileira para a Flórida ajuda a explicar o porquê de cidades como Pompano Beach, Deerfield Beach, no norte do condado de Broward, e Boca Raton, no sul do condado de Palm Beach, serem densamente povoadas por imigrantes brasileiros. O custo de vida relativamente baixo nessas cidades (comparado a cidades mais ricas como Miami) atraiu

\footnotetext{
${ }^{47}$ Ibidem.

${ }^{48}$ BLOEM, op. cit.

${ }^{49}$ Apud ibidem, p. 25-26.
} 
brasileiros da classe trabalhadora com o objetivo de abrir pequenos negócios ao longo do final da década de 1990 e início dos anos $2000 .{ }^{50} \mathrm{O}$ presidente da Focus Brazil Foundation, Carlos Borges, classifica o primeiro quinquênio dos anos 2000 como "os anos dourados da imigração brasileira para o condado de Broward". ${ }^{51}$

No entanto, como aponta Bloem ${ }^{52}$, esse período também foi de dificuldade para muitos imigrantes "indocumentados". Segundo Alves e Ribeiro ${ }^{53}$, o atentado de 11 de setembro tornou ainda mais agudas as dificuldades já vivenciadas pelos imigrantes e gerou consequências específicas nas condições de vida dos brasileiros:

Afetou as condições de trabalho - 'o trabalho caiu muito, tem muita gente sem trabalho' - mas, sobretudo, representou um aumento de restrições à migração: os processos de legalização de documentos são muito mais lentos, há maiores exigências para conceder a 'drive-license' e intensificou-se o controle sobre pessoas "indocumentadas": houve gente que foi efetivamente presa e deportada. $^{54}$

O relato do presidente da Brazil International Foundation, Aloysio Vasconcellos ${ }^{55}$, que reside em Boca Raton, ajuda na compreensão desse período conturbado.

Eu vim para cá em 2000. [...] Quando eu cheguei aqui tinham muitos brasileiros "indocumentados". Você andava pelas ruas e esbarrava com brasileiros. Você chamava por serviços domésticos, vinham brasileiros. Houve um aperto por parte das autoridades, que usaram muito a polícia. Não a polícia catando as pessoas, mas, por exemplo, no trânsito. Quando você batia com o carro, os policiais queriam os documentos do carro. Se você não tivesse a carteira de identidade, eles o reportavam, coisa que não faziam antes. Passaram a ter carros da polícia com agentes da imigração e vice-versa. Mesmo nas escolas, passaram a exigir mais documentação. Isso tudo foi dificultando a vida das pessoas. Muitos voltaram para o Brasil.

Sobre os atentados de 11 de Setembro, Magalhães ${ }^{56}$ aponta que, dentre os imigrantes que estavam nos Estados Unidos naquele momento, muitos

\footnotetext{
${ }^{50}$ Ibidem.

${ }^{51}$ Apud ibidem, p. 27.

${ }^{52}$ Ibidem.

${ }^{53}$ ALVES, José Cláudio Souza; RIBEIRO, Lúcia. "Migração, religião e transnacionalismo: o caso dos brasileiros no sul da Flórida". In: Religião e Sociedade. Rio de Janeiro, v. 22, 2002.

${ }^{54}$ Ibidem, p. 15-16.

${ }^{55}$ Entrevista concedida por Aloysio Vasconcellos no dia 21 de setembro de 2016.

${ }^{56}$ MAGALHÃES, O Brasil no Sul da Flórida... op. cit.
} 
sentimentos se passaram: medo, vontade de voltar para o Brasil, identificação com o nacionalismo norte-americano, decepção com os Estados Unidos ou reorientação de projetos migratórios. Segundo a autora,

Tal advento foi significativo para os nossos conterrâneos, bem como para todas as outras nacionalidades, pois acentuou a perseguição do governo americano aos "indocumentados" e provocou muitos retornos. Sob outra ótica, o atentado também representou a decepção com a América. ${ }^{57}$

\section{De acordo com a presidente da Central Florida Brazilian American Chamber of Commerce (CFBACC), Laiz Rodrigues ${ }^{58}$,}

Depois do onze de setembro, tudo mudou. Em 2001, 2002, a América acordou achando que tinha que se proteger mais do que nunca. Mudou a documentação, a maneira que recebia as pessoas, e passou a ser mais exigente. $O$ que aconteceu? Houve um esvaziamento de imigrantes. Foi todo mundo embora. Nessa época, o Brasil também começou a melhorar. Quando veio 2008, com a crise nos Estados Unidos, a coisa piorou ainda mais. Em 2009, foi muita gente embora, igrejas ficaram esvaziadas, muitos trabalhos foram largados por aí.

Assim como Laiz Rodrigues, a editora da revista Linha Aberta e presidente da ABI-INTER (Associação Brasileira de Imprensa Internacional), Laine Furtado ${ }^{59}$, aponta que a crise econômica de 2007-2008 foi um fator importante na decisão de retornar ao Brasil. Além disso, chama atenção para a chegada, nos últimos anos, de um "novo perfil" de brasileiros.

Com a crise de 2007, muita gente voltou. [...] estava havendo uma pressão muito grande em relação aos imigrantes ilegais. Faltou dinheiro. Então, em função da pressão de estar sem dinheiro, ilegal, carteira de motorista vencida, muitos, muitos retornaram porque se viram sem opção. Mas, em 2010, 2011, mais ou menos, começamos a ver a chegada de outro perfil de brasileiro, que eram os brasileiros que estavam investindo. O Brasil estava num boom, e esses brasileiros começaram a investir em second homes e começaram a se fixar muito nessa área de Miami, de SunnyIsles, essa área mais para o sul. Esse povo que chegou em 2010 a 2013, 2014, era um povo que na verdade não residia aqui nos Estados Unidos. Tinham aqui como uma segunda residência. Mas, com a crise no Brasil, volta-se um novo perfil de brasileiros, que são os brasileiros que não estão vindo para cá somente com a intenção de investir, mas de abrir o seu negócio aqui, e se mudar do Brasil para os Estados Unidos. ${ }^{60}$

\footnotetext{
${ }^{57}$ Ibidem, p. 62.

${ }^{58}$ Entrevista concedida por Laiz Rodrigues no dia 12 de setembro 2016.

${ }^{59}$ Entrevista concedida por Laine Furtado no dia 19 de setembro de 2016.

${ }^{60}$ Entrevista concedida por Laine Furtado no dia 19 de setembro de 2016.
} 


\section{Terceira onda}

Bloem ${ }^{61}$ acredita estar no meio da terceira onda da imigração brasileira para a Flórida. Ao longo dos últimos anos (desde aproximadamente 2010), inúmeros brasileiros mais ricos (Classe A) estão migrando para a área de Miami. Em suas entrevistas, o autor identificou como explicação predominante: brasileiros ricos não se sentem mais seguros no Brasil, tanto fisicamente como economicamente. Nas palavras do professor Parente:

The rich are fed up with Brazil in regard to violence and corruption, so some of the rich folks are actually moving their families to Miami... running their business in Brazil and living in Miami... They feel safer with their families in Miami [...]. The political and economic instability associated with the scalating violence serve as a huge incentive for the rich people to make investments in the US, where Miami and Orlando are preferred choices because of the language and Latin culture. ${ }^{62}$

\section{Segundo a co-fundadora e presidente do Centro Cultural Brasil-USA da Flórida (CCBU), Adriana Sabino ${ }^{63}$,}

Tem muita gente vindo para cá. São famílias de profissionais. Não são mais aqueles brasileiros que vinham para assentar piso em Pompano. É gente que tem negócios no Brasil, que fechou os negócios, ou que está deixando a distância... Gente que é de alto nível acadêmico. Eu acho que é uma loucura, porque eles estão aqui usando o dinheiro do Brasil. Não sei como vão se sustentar aqui, porque a maioria não pode trabalhar. Estão detonando suas economias. É uma loucura!

\section{De acordo com Aloysio Vasconcellos ${ }^{64}$,}

Essa onda é uma onda que traz muito business development, empreendedorismo, crescimento, utilizando o que os Estados Unidos tem de interessante. Eles [os imigrantes brasileiros] vêm e procuram ser bem assessorados por empresas, até de brasileiros que estão aqui há algum tempo, e de outras que estão vindo. Isso implica num esvaziamento brasileiro, mas está realmente acontecendo. Eu sei de casos aqui na Flórida de pessoas que saíram e que hoje estão dando aulas aqui, fazendo pesquisas. Às vezes, a gente pensa que a área empresarial não é tão sofisticada [...], mas nós temos mestrandos, pessoas com masters que vêm para cá, e aqui ficam. Formam-se aqui e não querem voltar para o Brasil... Casam-se com uma americana. Perda de cérebros! Isso é contínuo, e está se acelerando.

\footnotetext{
${ }^{61}$ BLOEM, op. cit.

${ }^{62}$ Apud ibidem, p. 27-28.

${ }^{63}$ Entrevista concedida por Adriana Sabino no dia 22 de setembro de 2016.

${ }^{64}$ Entrevista concedida por Aloysio Vasconcellos no dia 10 de janeiro de 2017.
} 
Como apontam Lima e Castro,

outra característica desse novo fluxo é o fato de mais famílias chegarem completas aos Estados Unidos. Diferentemente da maioria da maioria dos imigrantes brasileiros das últimas décadas, que empreendiam sozinhos a viagem, agora percebe-se mais pessoas de um mesmo grupo familiar fazendo, juntas, a jornada migratória. ${ }^{65}$

\section{Considerações finais}

O desenvolvimento do presente trabalho possibilitou uma análise da história da imigração de brasileiros para o Sul da Flórida durante o período de tempo compreendido entre 1980 até 2016.

Constatou-se que o marco inicial da presença brasileira no Sul da Flórida são os anos 1980. Desde os anos 1980, diferentes levas de imigrantes brasileiros têm se dirigido ao Sul da Flórida. Historicamente, essas ondas migratórias estiveram associadas aos seguintes fatores, no caso de Miami-Dade: entrada de empresas multinacionais em Miami, a partir da década de 1980; o Plano Collor (decretado em 12 de abril de 1990); a paridade do real em relação ao dólar (em 1ํo de julho de 1994); a desvalorização do real em relação ao dólar (em 15 de janeiro de 1999); a crise econômica do Brasil provocada pelo Plano Real (e acentuada após 1999) e os atentados de 11 de Setembro de 2001. Mais recentemente, podemos destacar a crise econômica mundial de 2008 que estimulou o retorno de alguns brasileiros que viviam em outros países; a eleição e o impeachment de Dilma Roussef e a eleição de Donald Trump, em 2016.

Os condados de Broward e, mais recentemente, Palm Beach também atraíram brasileiros por motivos diversos, tais como as igrejas evangélicas que enviaram missionários para a região; a força de atração das redes de amigos e parentes e a chegada de imigrantes que viviam em outras partes dos Estados Unidos para abrirem negócios na Flórida.

Através das entrevistas com informantes-chave e da pesquisa bibliográfica, concluiu-se que, atualmente, ocorre a terceira onda da imigração para a Flórida. O que diferencia a atual das anteriores é a chegada, em grande número, de brasileiros com grau superior de instrução e/ou com alta qualificação nas diversas áreas de sua atuação profissional.

Artigo recebido para publicação em 01/05/2018

Artigo aprovado para publicação em 25/10/2018

${ }^{65}$ LIMA, Álvaro Eduardo de Castro; CASTRO, Alanni de Lacerda Barbosa de. Brasileiros nos Estados Unidos: meio século (re)fazendo a América (1960-2010). Brasília: FUNAG, 2017, p. 116. 